\title{
False-negative Diffusion-weighted Imaging in a Patient with Basilar Artery Syndrome Presenting with Isolated Vertigo
}

\author{
İzole Vertigo ile Başvuran Baziler Arter Sendromlu Bir Hastada Yanlış-negatif Difüzyon-
} ağırlıklı Görüntüleme

Keywords: False-negative DWI, basilar artery syndrome, isolated vertigo, emergency department, diagnosis

Anahtar Kelimeler: Yanlış-negatif DAG, baziler arter sendromu, izole vertigo, acil servis, tanı

\section{Dear Editor,}

A 69-year-old female patient with medical history of hypertension and diabetes mellitus was admitted to the emergency department with symptoms of vertigo and nausea/vomiting, which had started three hours prior to admission. On examination, she was evaluated as orientated and cooperated. Motor and sensory examinations were within normal limits. However, other examinations by the emergency physician could not be properly performed due to severe vomiting. Cranial diffusion-weighted imaging (DWI) showed normal findings (Figure 1A). Taken together, a neurologic aetiology was not considered. Laboratory examinations showed mild leukocytosis and normal biochemistry results. In addition, mild fever was detected. The patient was hospitalised by the department of internal medicine and during the following 3-day period, she was evaluated as orientated and cooperated, but she was immobile due to severe nausea and vomiting. However, on the third day of hospitalization, when she woke up, dysarthria and impairment in consciousness were noticed. Neurology consultation was requested and after an evaluation a second DWI was ordered, which showed diffusion-restricted regions in the brain stem and left cerebellum (Figure 1B). Aspirin and enoxaparin were initiated. However, her neurologic status deteriorated on the following day, such that she was only able to cooperate with eyelid movements, compatible with locked-in syndrome. Cranial DWI showed the progression of the infarct (Figure 1C, D). Brain/neck computed tomography showed critical stenosis of the basilar artery. Enoxaparin was switched to heparin infusion and high-dose atorvastatin was added. However, unfortunately, the patient was evaluated as comatose with Glasgow Coma scale score of 3 in an evaluation on the following day. In the third month of follow-up in the intensive care unit, cardiac arrest occurred following pneumonia-related septic shock.

Isolated vertigo/vomiting mostly comes from peripheral vestibular diseases (1). On the other hand, strokes, particularly in the distribution of the posterior circulation, may also frequently present with vertigo, nausea/vomiting (2). Although vertigo due to stroke usually manifests with other neurologic symptoms, it is known that isolated vertigo from ischemic origin is not a rare event. Through innovations in advanced neuroimaging techniques and clinical experience in the stroke field, isolated vertigo due to cerebellar and small brain stem infarctions is increasingly recognized in clinical concerns (3). The mechanisms underlying nausea/vomiting and vertigo have been explained in the setting of vestibular dysfunction or involvement of the dorsal tegmentum (the vomiting center) on the floor of the fourth ventricle. Remarkably, accurate and timely diagnosis of vertigo from an acute vascular origin is very critical as misdiagnosis may result in significant morbidity and mortality (2). On the other hand, in a crucial study, stroke was found to be responsible for $3.2-4.0 \%$ of patients admitted to the emergency department due to dizziness and vertigo (4). Hence, it has also been emphasized that overdiagnosis of vascular vertigo could otherwise lead to unnecessary examinations and medications (2). Herein, we illustrate an extremely rare patient in whom the clinical presentation was in the form of isolated vertigo and nausea/vomiting of vascular origin, and more remarkably, cranial

\footnotetext{
Address for Correspondence/Yazışma Adresi: Halil Önder MD, Yozgat City Hospital, Clinic of Neurology, Yozgat, Turkey

Phone: +903544442066 E-mail: halilnder@yahoo.com ORCID: orcid.org/0000-0002-1823-2278

Received/Geliş Tarihi: 12.04.2019 Accepted/Kabul Tarihi: 05.12.2019

${ }^{\circledR}$ Copyright 2020 by Turkish Neurological Society

Turkish Journal of Neurology published by Galenos Publishing House.
} 

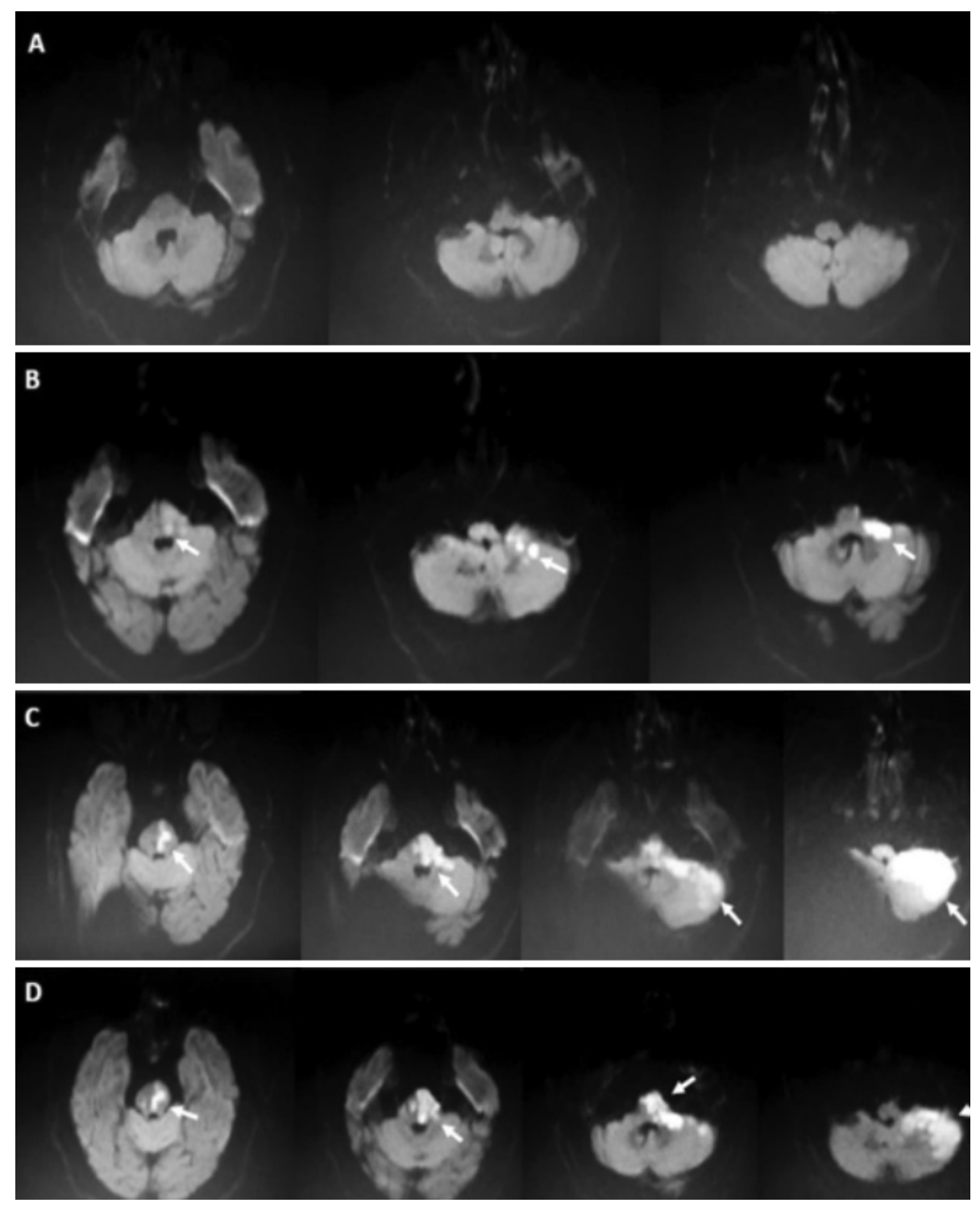

Figure 1. A) Diffusion-weighted imaging (DWI) performed, at first admission, showing normal findings. B) Second DWI, performed after clinical worsening on the third day of hospitalisation, showing diffusion restriction of rostral pons and left superior cerebellum. C) Third DWI, performed on the fourth day of admission, showing the progression of diffusion restriction to involve pontine tegmentum, medulla, inferior cerebellar peduncle (compatible with locked-in syndrome). D) Fourth DWI showing the progression of diffusion restriction to bilateral pontine tegmentum and medulla oblongata

DWI was in normal ranges, which suggested aetiologies other than stroke. However, the patient deteriorated on the third day of follow-up and the clinical course was devastating despite intensive medical interventions initiated soon after the diagnosis of basilar artery syndrome. Via the presentation of this patient, we re-draw attention to the presence of isolated vascular vertigo that may not be detected in the initial magnetic resonance imaging (MRI), as in this case. We would like to discuss the limitation of MRIbased diagnosis and stress the importance of bedside evaluation of vertigo, which was also previously emphasized to be superior to MRIs for detecting central vascular vertigo syndromes (3). It is the author's belief that clinical suspicion of vascular vertigo should prompt early repetition of DWIs, and vascular imaging examinations may also be performed in these conditions. However, the utility and cost-effectiveness of this consideration surely need to be investigated in future larger case series.

On the other hand, episodic vertigo in association with vertebrobasilar insufficiency has been acknowledged for a long time because it can manifest with or without other signs of brain stem and/or cerebellum infarction. Interestingly, in a large group of patients with vertigo of presumed vascular origin, $29 \%$ were determined to have at least one episode of vertigo before the infarction (5). The preference in this case report was to identify the patient as having 'false-negative MRI in basilar artery syndrome'. 
However, a major point of discussion is whether it is more rationale to describe our case as 'false-negative MRI in basilar artery syndrome' or 'episodic vertigo preceding basilar artery syndrome'. Future studies on larger patient groups including serial DWIs and perfusion techniques may provide substantial contributions to our understanding of the underlying pathophysiologies in these manifestations, as well as the diagnostic borderlines of DWI in acute stroke syndromes.

\section{Ethics}

Informed Consent: Patient consent was obtained.

Peer-review: Externally peer-reviewed.

Conflict of Interest: The authors declared that this study received no financial support.

\section{References}

1. Baloh RW. Clinical practice. Vestibular neuritis. $\mathrm{N}$ Engl J Med 2003;348:1027-1032.

2. Choi KD, Lee H, Kim JS. Vertigo in brainstem and cerebellar strokes. Curr Opin Neurol 2013;26:90-95.

3. Lee H. Isolated vascular vertigo. J Stroke 2014;16:124-130.

4. Newman-Toker DE, Hsieh YH, Camargo CA, Pelletier AJ, Butchy GT, Edlow JA. Spectrum of dizziness visits to US emergency departments: crosssectional analysis from a nationally representative sample. Mayo Clin Proc 2008;83:765-775.

5. Grad A, Baloh RW. Vertigo of vascular origin. Clinical and electronystagmographic features in 84 cases. Arch Neurol 1989;46:281-284. 